\title{
IMPLEMENTASI METODE ALGORITMA KVC UNTUK PENGAMANAN PESAN
}

\author{
Yunita Achsanti ${ }^{1}$, Heru Abrianto ${ }^{2}$, Ninuk Wiliani ${ }^{3}$ \\ Program Studi Teknik Elektro/Telekomunikasi, Fakultas Teknologi Industri \\ Program Studi Teknik Informatika, Fakultas Sains dan Teknologi Industri \\ Institut Sains dan Teknologi Nasional \\ Jl. M.Kahfi II Bhumi Srengseng Indah, Jagakarsa, Jakarta Selatan, telp 021-7270090 \\ yunita.achsanty@gmail.com, heru@istn.ac.id,ninukwiliani15@gmail.com
}

\begin{abstract}
Communication through message media or sms, Sort Message Service is not a point to point message but that communication by sent through sms network and stored in database operator. Message security on the network is threatened be read by people who are not responsible or called intercept. Therefore it will be develop some application on the mobile phone to modify the message be come a Ciphertext and the information content of the messageis not known by others. In this application, the system encrypts the message into Ciphertext using the key entered by the sender and then it will be sends to the destination number. For accepting the message, system will decrypt chipertext become plaintext using key by sender, then the message can be read by receiver. This application can be used by some one who wants to sending the secret message and very important without fear if the information can read by others. This application uses Vigenere Cipher method. The main parameter is the key and the message itself.
\end{abstract}

Keywords: Sort Message Service (SMS), Encryption, Decryption, Cryptography, Vigenere Cipher.

\begin{abstract}
Abstrak
Komunikasi melalui media pesan atau SMS, Sort Message Service bukan merupakan pesan point-topoin melainkan komunikasi yang dikirimkan melalui jaringan SMS dan tersimpan pada database operator yang bersangkutan. Pada jaringan tersebut, keamanan pesan sangat terancam untuk dibaca oleh orang yang tidak bertanggung jawab atau yang populer dengan istilah penyadapan. Oleh karena itu akan dikembangkan sebuah aplikasi pada telepon selular untuk memodifikasi pesan menjadi Ciphertext agar isi informasi dari pesan tersebut tidak diketahui oleh orang lain. Dalam aplikasi ini, sistem mengenkripsi pesan menjadi Ciphertext menggunakan kunci yang diinputkan oleh pengirim kemudian mengirimkan ke nomor tujuan. Untuk penerimaan pesan, sistem mendekripsi Ciphertext menjadi plaintext menggunakan key yang diinputkan oleh penerima kemudian menampilkan pesan asli kepada penerima. Aplikasi ini dapat dimanfaatkan oleh seseorang yang ingin mengirimkan suatu informasi rahasia kepada orang lain melalui SMS tanpa takut informasi dari pesan tersebut akan diketahui oleh orang lain. Metode yang digunakan aplikasi dalam mengenkripsi dan mendekripsi pesan adalah metode algoritma kriptografi Vigenere Cipher (KVC) dengan parameter utamanya adalah kunci, dan pesan itu sendiri.
\end{abstract}

Kata Kunci: Sort message service (SMS), enkripsi, dekripsi, kriptografi, Vigenere Cipher.

\section{PENDAHULUAN}

Perkembangan teknologi di bidang telekomunikasi khususnya dalam perkembangan teknologi seluler terlihat sangat pesat. Kini, perangkat seluler ada yang telah memiliki spesifikasi setara dengan notebook dan netbook. Sehingga sebagian besar kegiatan yang dilakukan di perangkat notebook dan netbook, kini bisa dilakukan di perangkat seluler. Perangkat ini biasa disebut Smartphone. Oleh karenanya, masyarakat lebih memilih menggunakan smartphone untuk mendukung aktifitas hariannya karena lebih simpel, efektif dan efisien. Sejalan 
dengan itu semua, kejahatan di dunia cyber makin merebak. Salah satu sasarannya yaitu media perpesanan atau SMS. Komunikasi melalui media pesan atau SMS ini bukanlah komunikasi point-to-point. Pesan yang dikirimkan melalui media pesan tidak langsung sampai pada tujuan, melainkan melalui jaringan SMS dan tersimpan pada database operator yang bersangkutan. Pada jaringan SMS tersebut, keamanan pesan sangatlah terancam untuk dibaca oleh orang yang tidak bertanggung jawab atau yang populer dengan istilah penyadapan[7]. Untuk membantu pengguna dalam mengamankan pesannya, agar tidak ada pihak yang tidak dikehendaki yang dapat membacanya, akan dikembangkan sebuah aplikasi dengan menggunakan metode Algoritma Vigenere yang bertujuan untuk mengamankan sebuah pesan terkirim.

Short Message Service (SMS) merupakan sebuah layanan yang banyak diaplikasikan pada sistem komunikasi tanpa kabel, memungkinkan dilakukannya pengiriman pesan dalam bentuk alphanumeric antara terminal pelanggan atau antara terminal pelanggan dengan sistem eksternal seperti email, paging, voice mail, dan lain - lain. Disebut pesan teks pendek karena pesan yang dikirimkan hanya berupa karakter[4]. Teknologi yang mendukung SMS antara lain adalah Global System for Mobile (GSM), Time Division Multiple Access (TDMA) dan Code Division Multiple Access (CDMA). Dengan didukung oleh ketiga teknologi ini, SMS telah menjadi layanan data bergerak yang bersifat universal.

\section{METODOLOGI PENELITIAN}

\subsection{Kriptografi}

Kriptografi adalah sebuah ilmu yang mempelajari bagaimana cara menjaga agar data atau pesan tetap aman saat dikirimkan, dari pengirim ke penerima tanpa mengalamigangguan dari pihak ketiga. Menurut Bruce Scheiner dalam bukunya "AppliedCryptography", kriptografi adalah ilmu pengetahuan dan seni menjaga pesan (informasi)agar tetap aman (secure) ${ }^{[2]}$. Pada bidang kriptografi terdapat istilah-istilah yang digunakan, seperti plaintext, chipertext, enkripsi, dekripsi, dan kunci. Dimana, Plaintext (M) adalah pesan yang hendak dikirimkan (berisi data asli), Chipertext (C) adalah pesan ter-enkrip (tersandi) yang merupakan hasil enkripsi, Enkripsi adalah proses pengubahan plaintext menjadi Ciphertext, Dekripsi adalah kebalikan dari enkripsi yakni mengubah Ciphertext menjadi plaintext, sehingga berupa data awal/asli, dan Kunci adalah suatu bilangan yang dirahasiakan yang digunakan dalam proses enkripsi dan dekripsi. Hal-hal tersebut merupakan dasar dari struktur enkripsi dekripsi seperti pada gambar $1^{[5] .}$

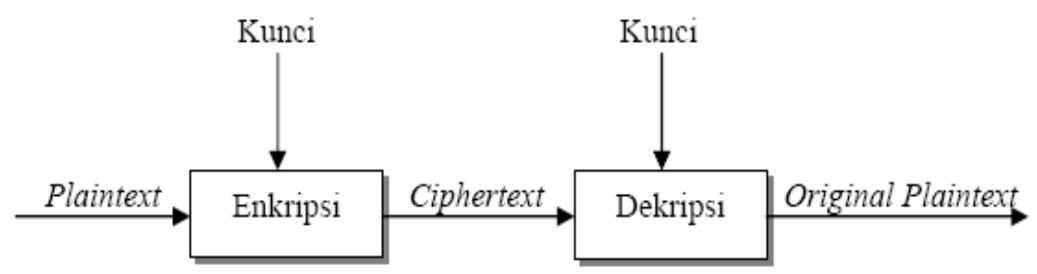

Gambar 1. Proses Kriptografi 


\subsection{Algoritma Kriptografi Caesar Cipher}

Nama Sandi Caesar diambil dari Julius Caesar, yang menurut buku Suetonius Kehidupan Dua belas Caesar, menggunakan sandi ini dengan geseran tiga, untuk mengirim pesan yang mengandung rahasia atau taktik militer.

Caesar Cipher sering juga disebut dengan shift Cipher, karena dasar dari algoritma ini adalah dengan menggeser beberapa karakter dari plaintext.

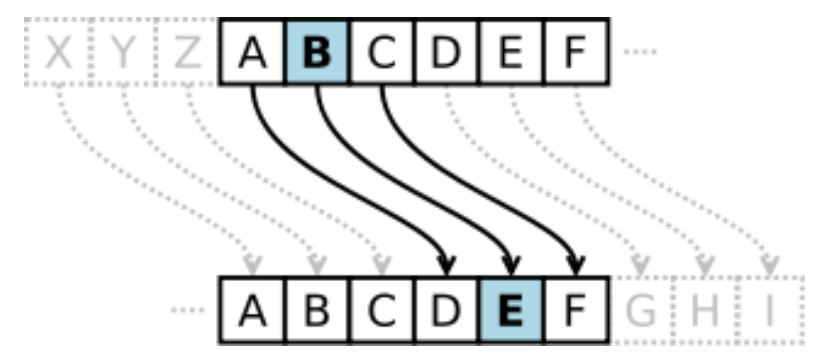

Gambar 2. Metode Kriptografi Caesar Cipher

Pada gambar 2 merupakan contoh dari metode kriptografi caesar Cipher dengan menggeser 3 karakter. Misalnya, plaintext pada huruf A jika digeser 3 karakter maka menghasilkan Ciphertext huruf D, plaintext pada huruf B jika digeser 3 karakter maka menghasilkan Ciphertext huruf E, plaintext pada huruf C jika digeser 3 karakter maka menghasilkan Ciphertext huruf F, dan begitu seterusnya.

\subsection{Enkripsi Kriptografi Caesar Cipher}

Untuk melakukan enkripsi dari caesar Cipher, dapat diambil rumus untuk enkripsinya adalah sebagai berikut:

$\mathrm{E}(\mathrm{x})=(\mathrm{x}+\mathrm{key}) \bmod 25$

Nilai mod 25, bukan mod 26 karena index karakter memulai dari 0 . (A = 0, B = 1, C $=2, \ldots, \mathrm{Z}=25$ )

\subsection{Deskripsi Kriptografi Caesar Cipher}

Untuk melakukan dekripsi dari caesar Cipher, harus melakukan pembalikan rumus enkripsinya[3]:

Dari $\mathbf{E}(\mathbf{x})=(\mathbf{x}+\mathbf{k e y}) \bmod 25$

Menjadi $\mathbf{D}(\mathbf{x})=(\mathrm{x}-\mathrm{key}) \bmod 25$

\subsection{Android}

Android adalah sebuah sistem operasi untuk perangkat mobile berbasis linux yang mencakup sistem operasi, middleware, dan aplikasi. Android menyediakan platform yang terbuka bagi para pengembang untuk menciptakan aplikasi. Awalnya, Google Inc. Mengakuisisi Android Inc. Yang merupakan pendatang baru sebagai pembuat piranti lunak ponsel atau smartphone. Saat ini Android diklaim sebagai platform mobile pertama yang lengkap. Terbuka, dan bebas ${ }^{[6]}$. 
Untuk mengimplementasikan algoritma pengacak pesan, maka dibangun aplikasi Secure SMS. Aplikasi tersebut menggunakan metode algoritma KVC yang berperan untuk mengenkripsi dan mendeskripsi pesan.

Sebelum membangun aplikasi Secure SMS ini, terlebih dahulu harus mengetahui tentang apa saja yang diperlukan untuk membuat aplikasi tersebut. Software dapat di download sendiri tanpa harus membelinya. Berikut peralatan atau software yang digunakan untuk membangun aplikasi tersebut.

Software pendukung yang digunakan untuk membuat aplikasi adalah eclipse juno versi 3.8 windows 32 bit, android sdk versi 24.1.1, perangkat PC dengan minimal RAM 2GB \& minimal free HDD 50GB, dan java jdk minimal versi 7 untuk bisa menjalankan eclipse juno seperti dijelaskan pada tabel 1.

Tabel 1. Software Pendukung

\begin{tabular}{llll}
\hline Equipment & Version & Size & Keterangan \\
\hline Eclipse Juno & 3.8 windows 32bit & $179 \mathrm{MB}$ & Release 2012 \\
Android SDK & 24.1 .1 & $149 \mathrm{MB}$ & 149 MB - 50 GB \\
Perangkat PC & Windows 7 32 bit & Min RAM 2 GB & $\begin{array}{l}\text { Free HDD mengacu } \\
\text { pada besaran size } \\
\end{array}$ \\
Intel core 2 duo & Min free HDD 50GB & $\begin{array}{l}\text { android SDK } \\
\text { Di atas versi 7 }\end{array}$ \\
\hline
\end{tabular}

Penelitian ini menggunakan dua buah perangkat untuk pengujian. Satu perangkat sebagai pengirim dan perangkat lainnya sebagai penerima. Perangkat yang digunakan sebagai pengirim adalah xiomi redmi 4x dan perangkat yang digunakan sebagai penerima adalah LG G3 dengan spesifikasi minimum seperti yang dijelaskan pada tabel 2 .

Tabel 2. Spesifikasi perangkat Android yang digunakan

\begin{tabular}{llll}
\hline Spesifikasi & \multicolumn{1}{c}{$\begin{array}{c}\text { Xiaomi Redmi 4x } \\
\text { (Pengirim) }\end{array}$} & \multicolumn{1}{c}{$\begin{array}{c}\text { LG G3 } \\
\text { (Penerima) }\end{array}$} & Spesifikasi Minimum \\
\hline Layar & IPS-LCD 5.0 inches, 720x 1280 & $\begin{array}{l}\text { IPS-LCD 5,5 inches, } \\
\text { pixels }\end{array}$ & $\begin{array}{l}\text { 3,0 inches 240x320 } \\
\text { pixels }\end{array}$ \\
CPU & Qualcomm MSM8940 & $\begin{array}{l}\text { 1440x2560 pixels } \\
\text { Qualcomm }\end{array}$ & 512 MHz ARMv6 \\
& Snapdragon 435 Octa-core 1,4 & $\begin{array}{l}\text { MSM8974 AC } \\
\text { Shapdragon 801 }\end{array}$ \\
& GHz Cortex-A53 & Quad-core 2.5 GHz & \\
& & Krait 400 & \\
Memori & 32 GB, 3 GB RAM & 16 GB, 2GB RAM & 1 GB, 512 MB RAM \\
OS & AndroidOS v.6.0 & AndroidOS v 5.0 & AndroidOS v.2.3.3 \\
& (Marsmallow) & (Lolipop) & (Gingerbread) \\
\hline
\end{tabular}

Hal-hal yang dapat dilakukan pengguna terhadap sistem atau aplikasi Secure SMS dijelaskan dalam gambar 3. Hal yang dapat dilakukan pengirim adalah mengirimkan pesan yang telah di enkripsi ke nomor tujuan include tulis pesan, input kontak, input kunci, dan enkripsi pesan serta melihat dan membaca pesan di dalam kotak masuk. Hal yang dapat dilakukan penerima adalah mendekripsikan 
terlebih dahulu pesan yang di terima dalam bentuk terenkripsi include input kunci dan dekripsi pesan serta melihat dan membaca pesan di dalam kotak masuk

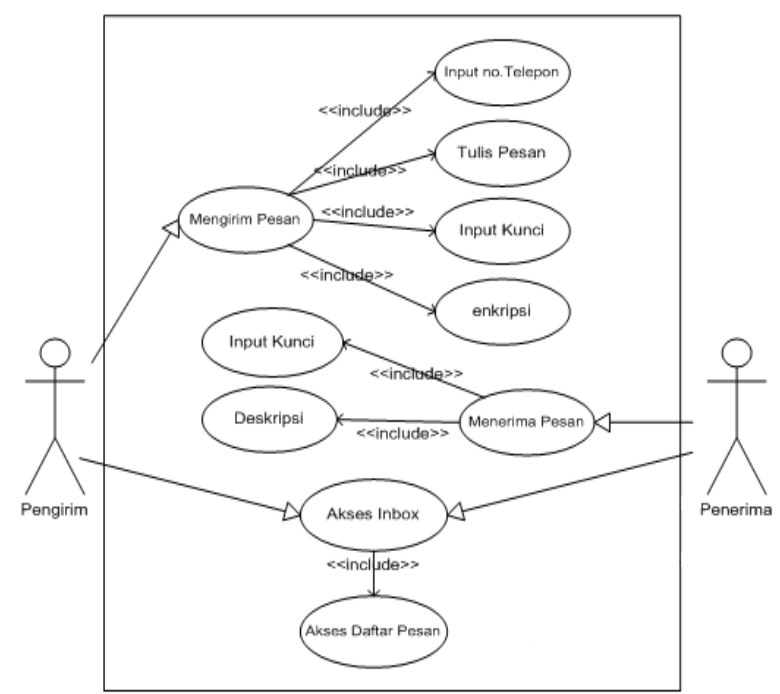

Gambar 3. Interaksi Diagram aplikasi

\subsection{Metode Algoritma Kriptografi Vigenere Cipher}

Vigenere Cipher merupakan bentuk pengembangan dari Caesar Cipher. Kelebihan sandi ini dibanding Caesar Cipher adalah Cipher ini tidak begitu rentan terhadap metode pemecahan Cipher. Vigènere Cipher menggunakan Bujursangkar Vigènere untuk melakukan enkripsi dan dekripsi. Jika pada Caesar Cipher setiap huruf digeser dengan besar geseran yang sama, maka pada Vigènere Cipher setiap huruf digeser dengan besar yang berbeda sesuai dengan kuncinya.

Algoritma enkripsi jenis ini sangat dikenal karena mudah dipahami dan diimplementasikan. Teknik untuk menghasilkan Ciphertext bisa dilakukan menggunakan substitusi angka maupun bujursangkar Vigenere. Teknik susbtitusi Vigenere dengan menggunakan angka dilakukan dengan menukarkan huruf dengan angka secara urut, di mulai dari huruf A-Z dan angka 0-25 seperti pada tabel 3.3.

Tabel 3. Substitusi Algoritma Kriptografi Vigenere Cipher

\begin{tabular}{|c|c|c|c|c|c|c|c|c|c|c|c|c|}
\hline A & B & C & D & E & F & G & H & I & J & K & I & M \\
\hline 0 & 1 & 2 & 3 & 4 & 5 & 6 & 7 & 8 & 9 & 10 & 11 & 12 \\
\hline
\end{tabular}

\begin{tabular}{|c|c|c|c|c|c|c|c|c|c|c|c|c|}
\hline N & O & P & Q & R & S & T & U & V & W & X & Y & Z \\
\hline 13 & 14 & 15 & 16 & 17 & 18 & 19 & 20 & 21 & 22 & 23 & 24 & 25 \\
\hline
\end{tabular}

Sedangkan teknik lain untuk melakukan proses enkripsi dengan metode Vigenere Cipher yaitu menggunakan tabula recta (disebut juga bujursangkar Vigenere) seperti pada gambar 4. Kolom paling kiri dari bujursangkar menyatakan hurufhuruf kunci, sedangkan baris paling atas menyatakan huruf-huruf plaintext. Setiap baris di dalam bujursangkar menyatakan huruf-huruf Ciphertext yang diperoleh 
Jurnal Riset Sistem Informasi Dan Teknik Informatika (JURASIK)

Volume (3) Juli 2018, pp 73-86

ISSN: 2527-5771/EISSN: 2549-7839

http://tunasbangsa.ac.id/ejurnal/index.php/jurasik

dengan Caesar Cipher, yang mana jumlah pergeseran huruf plaintext ditentukan nilai numerik huruf kunci tersebut (yaitu, $a=0, b=1, c=2, \ldots, z=25$ ).

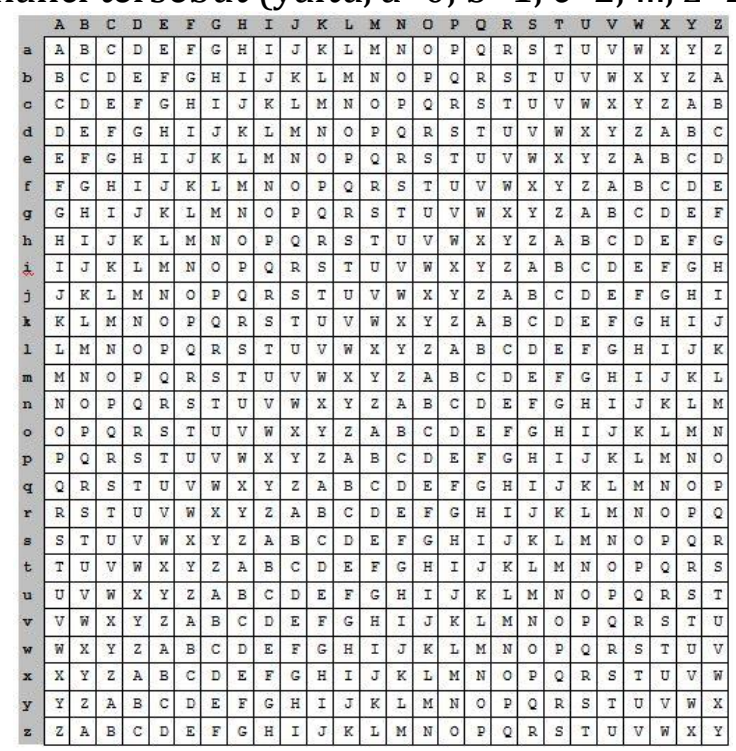

Gambar 4. Tabula Recta Algoritma Kriptografi Vigenere Cipher

\subsection{Perhitungan Manual Algoritma KVC}

Pada perhitungan manual ini diberikan contoh kunci dan plaintext sebesar 19 karakter. Dengan menggunakan rumus sebagai berikut:

Dimana:

$$
\begin{aligned}
& \mathrm{Ci}=(\mathrm{Pt}+\mathrm{K}) \bmod 26 \\
& \mathrm{Pt}=(\mathrm{Ci}-\mathrm{K}) \bmod 26
\end{aligned}
$$

$\mathrm{Ci}=$ nilai desimal karakter Cipher text ke-n

$\mathrm{Pt}=$ nilai desimal karakter plaintext ke-n

$\mathrm{K}=$ nilai desimal karakter kunci ke-n

Mod 26 = akan dilakukan perulangan jika melebihi 26

\section{Plaintext : SAYA YUNITA ACHSANTY MAHASISWI ISTN CIKINI YANG INGIN LULUS CUMLAUDE \\ Key : AMIN}

Proses Enkripsi Algoritma Kriptografi Vigenere Cipher

1. Menyamakan panjang key dengan panjang plaintext. \begin{tabular}{|l|c|c|c|c|c|c|c|c|c|c|c|c|c|c|c|c|c|c|}
\hline Plaintext & S & A & Y & A & Y & U & N & I & T & A & A & C & H & S & A & N & T & Y \\
\hline Key & A & M & I & N & A & M & I & N & A & M & I & N & A & M & I & N & A & M \\
\hline
\end{tabular}

2. Mengubah setiap huruf menjadi bilangan angka dan memasukannya ke dalam rumus.

\begin{tabular}{|l|c|c|c|c|c|}
\hline Plaintext & S & A & Y & A & \\
\hline Desimal Plaintext & 18 & 0 & 24 & 0 & \\
\hline Key & A & M & I & N & \\
\hline Desimal Key & 0 & 12 & 8 & 13 & \\
\hline
\end{tabular}

Implementasi Metode Algoritma KCV Pengaman Pesan(Yunita)| 78 

a. $\operatorname{Ci}(\mathrm{S})=(\mathrm{Pt}+\mathrm{K}) \bmod 26$
$\mathrm{Ci}(\mathrm{S}) \quad=(18+0) \bmod 26$
$\mathrm{Ci}(\mathrm{S})=(18)=\mathbf{S}$
b. $\mathrm{Ci}(\mathrm{A})=(\mathrm{Pt}+\mathrm{K}) \bmod 26$
$\mathrm{Ci}(\mathrm{A})=(0+12) \bmod 26$
$\operatorname{Ci}(\mathrm{A}) \quad=(12)=\mathbf{M}$
c. $\mathrm{Ci}(\mathrm{Y})=(\mathrm{Pt}+\mathrm{K}) \bmod 26$
$\mathrm{Ci}(\mathrm{Y})=(24+8) \bmod 26$
$\mathrm{Ci}(\mathrm{Y})=(32) \bmod 26$
$\mathrm{Ci}(\mathrm{Y})=(32-26)$
$\mathrm{Ci}(\mathrm{Y})=(6)=\mathbf{G}$
d. $\operatorname{Ci}(\mathrm{A})=(\mathrm{Pt}+\mathrm{K}) \bmod 26$
$\mathrm{Ci}(\mathrm{A})=(0+13) \bmod 26$
$\mathrm{Ci}(\mathrm{A}) \quad=(12)=\mathbf{N}$

3. Maka didapatkan hasil Ciphertext adalah SMGNYGVVTMIPHEIATK UNHMAVSIQVSFVPIWQAIKIAGUVTIZTHLGAPUYTNUPM.

Proses Deskripsi Algoritma Kriptografi Vigenere Cipher

1) Menyamakan panjang key dengan panjang Ciphertext.

\begin{tabular}{|l|c|c|c|c|c|c|c|c|c|c|c|c|c|c|c|c|c|c|}
\hline Plaintext & S & M & G & N & Y & G & V & V & T & M & I & P & H & E & I & A & T & K \\
\hline Key & A & M & I & N & A & M & I & N & A & M & I & N & A & M & I & N & A & M \\
\hline
\end{tabular}

2) Mengubah setiap huruf menjadi bilangan angka dan memasukannya ke dalam rumus.

\begin{tabular}{|c|c|c|c|c|c|c|c|c|c|c|c|c|c|c|c|c|c|}
\hline Plaintext & $\begin{array}{ll}M & G \\
\end{array}$ & $\mathrm{~N}$ & y & v & & $M$ & & $\mathrm{H}$ & & & & $\mathrm{k}$ & & H & A & $v$ & \\
\hline Desimal Plaintext & \begin{tabular}{l|l|l}
18 & 12 & 6 \\
\end{tabular} & 13 & 246 & 21 & & 912 & & 517 & 4 & & 19 & & 13 & & 0 & & $\begin{array}{ll}18 & 8 \\
\end{array}$ \\
\hline Key & \begin{tabular}{l|ll}
$A$ & $M$ & $I$ \\
\end{tabular} & $\mathrm{~N}$ & A 1 & & $\begin{array}{lll}N & A \\
\end{array}$ & $\mathrm{M}$ & & A & M & & A & M & N & A & & & $\begin{array}{lll} & M & 1 \\
\end{array}$ \\
\hline simal Key & \begin{tabular}{l|l|l|}
0 & 12 & 8 \\
\end{tabular} & 3 & & 8 & 0 & $2]$ & & 0 & 12 & & 0 & 128 & & & 8 & & \begin{tabular}{l|l|}
0 & 12 \\
\end{tabular} \\
\hline
\end{tabular}

a. $\operatorname{Pt}(\mathrm{S})=(\mathrm{Ci}-\mathrm{K}) \bmod 26$

$\operatorname{Pt}(\mathrm{S})=(18-0) \bmod 26$

$\operatorname{Pt}(\mathrm{S})=(18)=\mathbf{S}$

b. $\mathrm{Pt}(\mathrm{M})=(\mathrm{Ci}-\mathrm{K}) \bmod 26$

$P t(M)=(12-12) \bmod 26$

$\mathrm{Pt}(\mathrm{M})=(0)=\mathbf{A}$

c. $\operatorname{Pt}(\mathrm{G})=(\mathrm{Ci}-\mathrm{K}) \bmod 26$

$\mathrm{Pt}(\mathrm{G})=(6-8) \bmod 26$

$\mathrm{Pt}(\mathrm{G})=(-2) \bmod 26$

$\mathrm{Pt}(\mathrm{G})=(-2+26)$

$\mathrm{Pt}(\mathrm{G})=(24)=\mathbf{Y}$

d. $\operatorname{Pt}(\mathrm{N})=(\mathrm{Ci}-\mathrm{K}) \bmod 26$

$\mathrm{Pt}(\mathrm{N})=(13-13) \bmod 26$

$\operatorname{Pt}(\mathrm{N})=(0)=\mathbf{A}$

3) Maka didapatkan hasil plaintext adalah SAYA YUNITA ACHSANTY MAHASISWI ISTN CIKINI YANG INGIN LULUS CUMLAUDE.

\section{HASIL DAN PEMBAHASAN}

\subsection{Desain}

Pada setiap perancangan aplikasi, pasti akan menyinggung perihal desain. Desain disini lebih kepada pembahasan tentang bagaimana interaksi yang akan dibangun antara user dengan aplikasi, atau yang biasa disebut dengan user interface. 


\subsection{Rancangan Proses}

Pada Activity Diagram 5 diperlihatkan aktifitas yang dilakukan oleh pengirim terhadap sistem pada aplikasi Secure SMS. Mulai dari pengirim membuka aplikasi, mengakses form tulis pesan, input nomor tujuan, input kunci enkripsi, menuliskan pesan, mengenkripsi dan mengirim pesan atau SMS, sampai dengan pesan itu diterima oleh penerima.

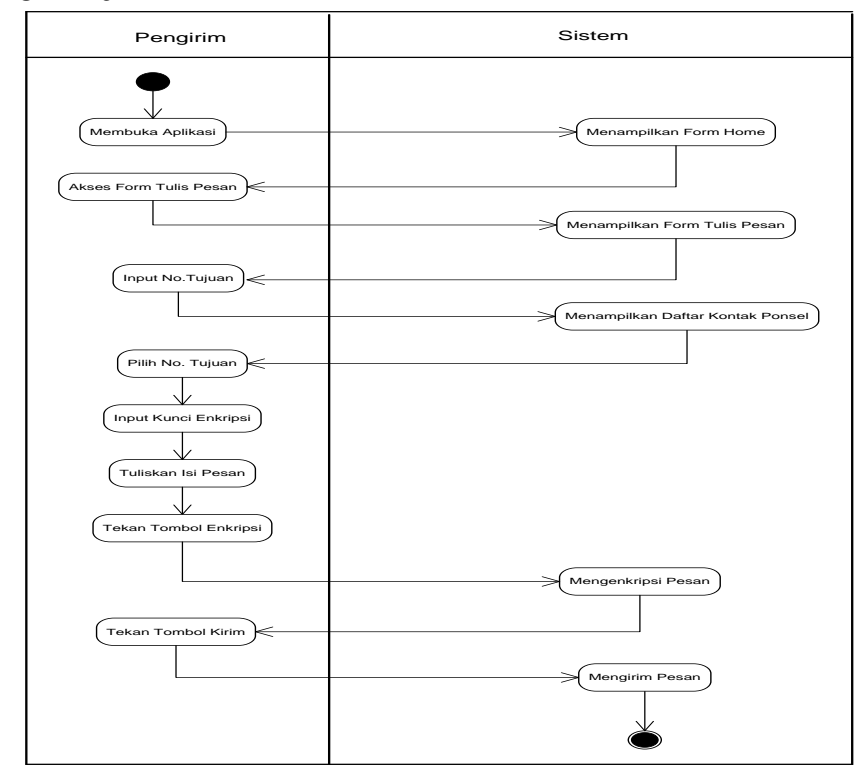

Gambar 5. Activity Diagram Pengirim

Pada Activity Diagram 6. diperlihatkan aktifitas yang dilakukan oleh penerima terhadap sistem pada aplikasi Secure SMS. Mulai dari penerima membuka aplikasi, mengakses form inbox, memilih pesan yang akan dideskripsikan, input kunci deskripsi, sampai dengan pesan itu menampilkan pesan aslinya.

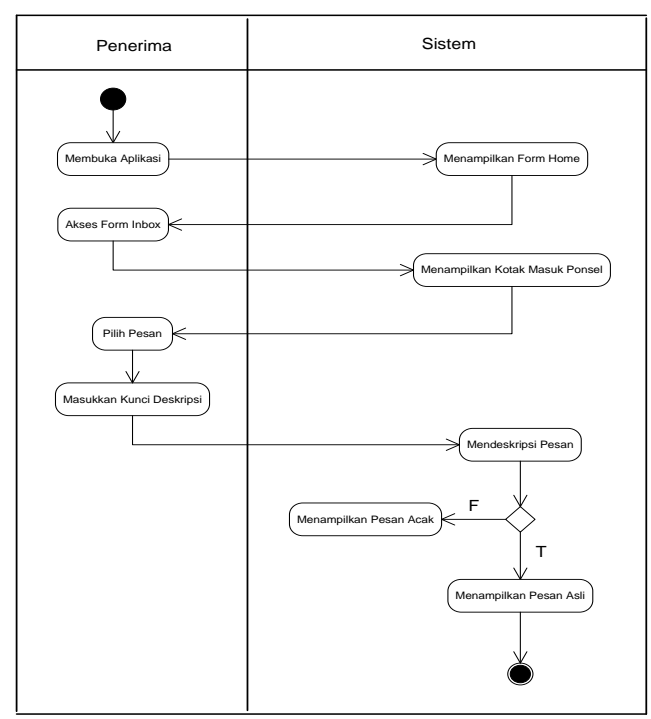

Gambar 6. Activity DiagramPenerima 


\subsection{Pengujian Proses}

Untuk lebih memastikan apakah algoritma yang dihitung manual berjalan sama persis pada aplikasi, maka dilakukan pembuktian pada aplikasinya langsung.

\subsubsection{Pengujian Enkripsi Pesan}

Pengujian dilakukan dengan meng-input nomor penerimanya, memasukan kunci dan isi pesan. Untuk kunci itu sendiri ditentukan atas dasar kesepakatan pihak pengirim dan penerima. Karena bila kunci berbeda maka kelak penerima tidak akan bisa mendeskripsikan pesan tersebut. Tombol enkripsi (icon gembok) akan bekerja bila pesan dan kunci sudah terisi. Begitu icon gembok diklik, maka hasil enkripsi akan tertampil dibawahnya. Lalu bisa mengirimkan pesan dengan menyentuh icon Kirim Pesan.

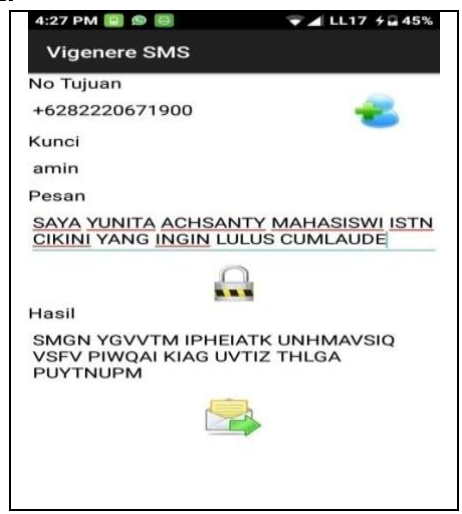

Gambar 7. Tampilan enkripsi pesan

Gambar 7 merupakan hasil dari perhitungan manual yang didapatkan hasil enkripsi dari pesan "Saya yunita achsanty mahasiswi istn cikini yang ingin lulus cumlaude" dengan kunci "Amin" adalah SMGN YGVVTM IPHEIATK UNHMAVSIQ VSFV PIWQAI KIAG UVTIZ THLGA PUYTNUPM.

\subsubsection{Pengujian Deskripsi Pesan}

Pesan yang telah terkirim akan sampai ke penerima. Penerima harus memiliki aplikasi yang sama dan mengetahui kunci yang sama untuk melakukan proses deskripsi. Untuk mengakses baca pesan dapat dilakukan dengan sentuh icon inbox pada halaman utama. Kemudian memilih pesan yang dimaksud, maka akan tampil seperti dibawah ini.

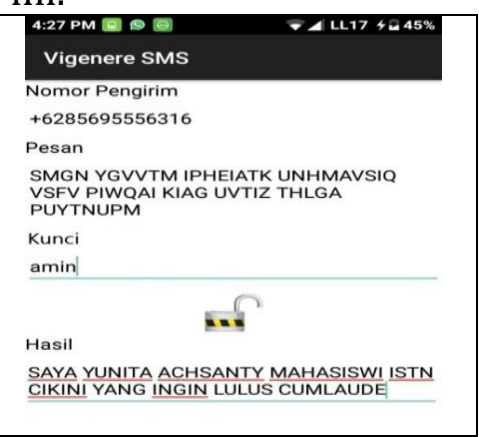

Gambar 8. Tampilan deskripsi pesan 
Secara default, user hanya harus menginputkan kuncinya. Dan jika tombol deskripsi (gembok terbuka) disentuh, maka hasil deskripsi akan tampil dibawahnya. Gambar 8 merupakan bukti dari perhitungan manual didapatkan hasil deskripsi dari pesan "Smgn ygvvtm ipheiatk unhmavsiq vsfv piwqai kiag uvtiz thlga puytnupm" dengan kunci "Amin" adalah SAYA YUNITA ACHSANTY MAHASISWI ISTN CIKINI YANG INGIN LULUS CUMLAUDE.

\subsection{Pengujian Kasus}

Proses pengujian dilakukan untuk mengetahui apakah data yang dimasukkan (input) sudah sesuai dengan yang diharapkan (output).

\subsubsection{Pengujian Ketika Kunci Belum Terisi}

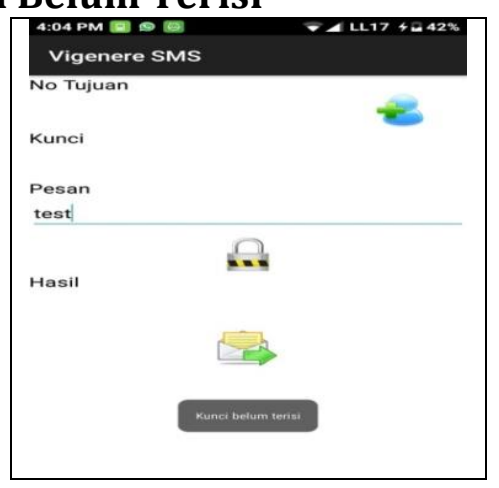

Gambar 9. Pesan peringatan kunci pesan belum terisi

Ketika kunci belum terisi namun isi pesan sudah terisi, maka saat klik tombol enkripsi (gembok), akan didapatkan pesan peringatan seperti pada gambar 9 "Kunci belum terisi".

\subsubsection{Pengujian Ketika Isi Pesan Belum Terisi}

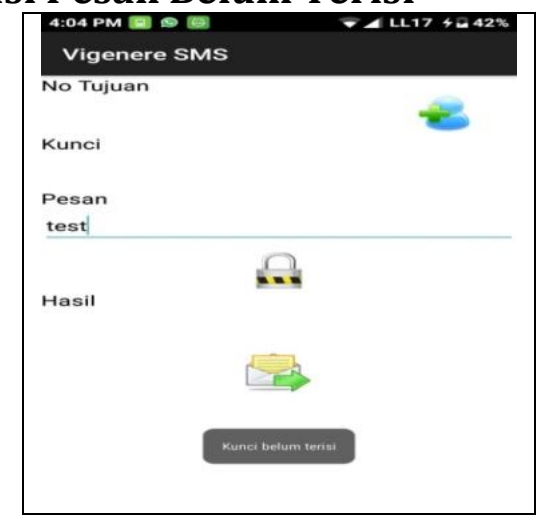

Gambar 10. Pesan peringatan isi pesan belum terisi

Ketika isi pesan belum terisi namun kunci sudah terisi, maka saat klik tombol enkripsi (gembok), akan didapatkan pesan peringatan seperti pada gambar 10 


\subsubsection{Pengujian Ketika Mengirim Pesan Tanpa Di Enkripsi}

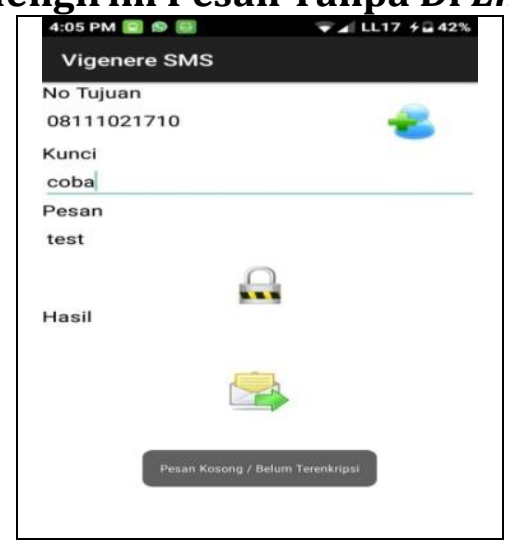

Gambar 11. Pesan peringatan mengirim pesan tanpa di enkripsi

Ketika isi pesan dan kunci sudah terisi namun belum di enkripsi, makasaat $k l i k$ tombol send, akan didapatkan pesan peringatan seperti pada gambar 11 .

\subsubsection{Pengujian Ketika Salah Memasukan Kunci}

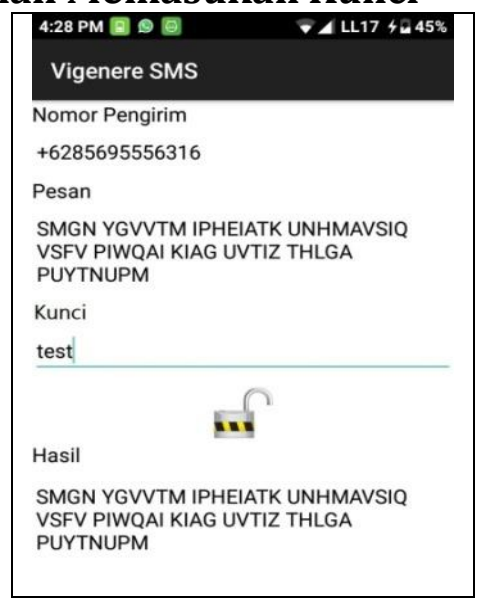

Gambar 12. Salah memasukkan kunci

Ketika pesan hendak didekripsi, saat input kunci namun kunci yang dimasukan salah, maka akan didapatkan pesan yang sama seperti pada gambar 12 Pesan tidak berubah / masih terenkripsi.

\subsection{Pengujian Kapasitas SMS \& Delay}

Proses pengiriman SMS pasti besinggungan dengan berapa besar data yang dapat dikirim dalam suatu proses dan berapa lama waktu yang dibutuhkan untuk proses tersebut.

\subsubsection{Waktu Pengiriman SMS}

Dalam pengaplikasiannya, proses pengiriman SMS sudah pasti memiliki jeda waktu bergantung pada panjang karakter pada SMS tersebut dan juga provider selular yang digunakan. Satu pengiriman SMS hanya dapat memuat 160 karakter. Sehingga bila lebih dari itu akan terhitung lebih dari 1 SMS dalam sekali pengiriman, dengan kata lain cost yang dikeluarkan juga akan lebih besar. Untuk mengetahui berapa waktu yang dibutuhkan untuk pengiriman pesan, dilakukan 
pengujian terhadap waktu kirim dan waktu terima pesan. Pengujian ini dilakukan pada dua pesan dengan panjang teks yang berbeda.

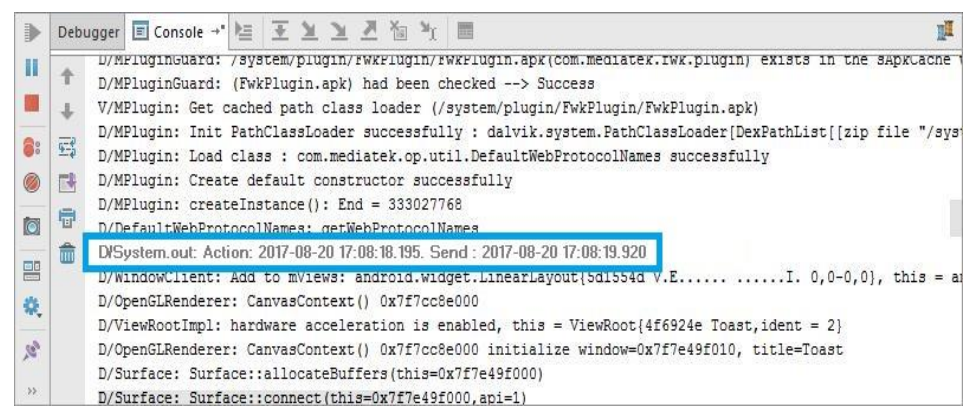

Gambar 13. Log Waktu Pengiriman SMS

Gambar 13 adalah tampilan log pada saat proses debug pada aplikasi console Eclipse yang menunjukkan lama waktu proses pengiriman SMS. Log yang ditampilkan adalah waktu aplikasi mulai menjalankan perintah kirim dan ketika status pesan terkirim. Contoh logdebug diatas adalah menggunakan 450 karakter (2 SMS dalam sekali kirim). Jadi dapat disimpulkan perhitungan waktu pengiriman SMS adalah waktu pesan terkirim dikurang waktu pesan di kirim. Pengujian dilakukan 5 kali untuk pengiriman jumlah SMS yang sama, namun jumlah karakter berbeda. Hasil pengukuran waktu SMS ditunjukkan pada tabel 4.

Tabel 4. Pengujian Waktu Pengiriman SMS

\begin{tabular}{cccc}
\hline Panjang Pesan & Panjang Chipertext & Jumlah SMS & Waktu Pengiriman \\
\hline 1 Karakter & 1 Karakter & 1 & $528 \mathrm{~ms}$ \\
15 Karakter & 15 Karakter & 1 & $399 \mathrm{~ms}$ \\
30 Karakter & 30 Karakter & 1 & $433 \mathrm{~ms}$ \\
64 Karakter & 64 Karakter & 1 & $442 \mathrm{~ms}$ \\
80 Karakter & 80 Karakter & 1 & $502 \mathrm{~ms}$ \\
161 Karakter & 161 Karakter & 2 & $865 \mathrm{~ms}$ \\
200 Karakter & 200 Karakter & 2 & $829 \mathrm{~ms}$ \\
240 Karakter & 240 Karakter & 2 & $717 \mathrm{~ms}$ \\
280 Karakter & 280 Karakter & 2 & $811 \mathrm{~ms}$ \\
320 Karakter & 320 Karakter & 2 & $816 \mathrm{~ms}$ \\
350 Karakter & 350 Karakter & 3 & $1.093 \mathrm{~s}$ \\
390 Karakter & 390 Karakter & 3 & $1.316 \mathrm{~s}$ \\
420 Karakter & 420 Karakter & 3 & $1.554 \mathrm{~s}$ \\
450 Karakter & 450 Karakter & 3 & $1.725 \mathrm{~s}$ \\
480 Karakter & 480 Karakter & 3 & $1.639 \mathrm{~s}$ \\
\hline
\end{tabular}

\subsubsection{Perhitungan Throughput}

Dapat dilihat pada tabel 6 bahwa panjang karakter pada plaintext (teks asli) dan karakter setelah proses enkripsi adalah sama. Hal ini menjadi salah satu keunggulan dari kesederhanaan enkripsi Vigenere dibanding algoritma enkripsi lain yang lebih rumit. Jumlah karakter menyebabkan pertambahan waktu lamanya 
pengiriman SMS, karena pertambahan karakter juga menambah jumlah SMS yang dikirim dalam 1 waktu.

Tetapi itu tidaklah mutlak, karena disi lain juga bergantung pada provider selular yang digunakan. Jadi bisa saja jumlah karakter SMS yang lebih sedikit memerlukan waktu kirim yang lebih lama dibanding jumlah karakter yang lebih banyak. Berikut dilakukan perhitungan untuk mengetahui rata-rata waktu pengiriman sesuai dengan jumlah SMS yang dikirimkan:

Rata-rata waktu pengiriman 1 SMS:

$\frac{528 \mathrm{~ms}+399 \mathrm{~ms}+433 \mathrm{~ms}+442 \mathrm{~ms}+502 \mathrm{~ms}}{5}=460,8 \mathrm{~ms}$

Rata-rata waktupengiriman 2 SMS:

$\frac{865 \mathrm{~ms}+829 \mathrm{~ms}+717 \mathrm{~ms}+811 \mathrm{~ms}+816 \mathrm{~ms}}{5}=807,6 \mathrm{~ms}$

Rata-rata waktupengiriman 3 SMS:

$1.093 \mathrm{~ms}+1.316 \mathrm{~ms}+1.554 \mathrm{~ms}+1.725 \mathrm{~ms}+1.639 \mathrm{~ms}$

$$
5 \text {. }=1.465 \mathrm{~ms}
$$

Dari perhitungan di atas dapat diketahui rata-rata waktu untuk pengiriman satu SMS adalah 460,8ms, waktu untuk pengiriman dua SMS adalah 807,6ms dan waktu untuk pengiriman tiga SMS adalah $1.465 \mathrm{~ms}$. Berdasarkan peningkatan jumlah SMS yang di kirimkan,waktu pengiriman juga mengalami peningkatan.

Dari perhitungan rata-rata tersebut diatas, dapat pula diketahui peningkatan waktu pengiriman 2 SMS ke 3 SMS dalam sekali kirim hampir satu kali lipat dibanding waktupengiriman satu SMS (1 SMS ke 2 SMS=346,8ms. 2 SMS ke 3 $\mathrm{SMS}=657,4 \mathrm{~ms}$ ). Jadi, dapat dihitung rata-rata waktu pengiriman dari ketiga SMS adalah $\pm 502 \mathrm{~ms}$. Setelah diketahui waktu pengiriman, maka dapat di hitung throughput sebagai berikut:

$$
\begin{aligned}
& \text { Throughput }=\frac{\text { JumlahDatayangDikirim }}{\text { WahtuPengiriman }} \\
& \frac{140}{502 \mathrm{~ms}}=0.2788 \text { Bytes } / \mathrm{ms}
\end{aligned}
$$

Jumlah data pada satuan SMS maksimum adalah 140Bytes, atau 160 karakter 7-bit. Berdasarkan perhitungan di atas, dapat diketahui bahwa throughput data pengiriman SMS adalah 0.2788 Bytes/s.

\section{SIMPULAN}

Berdasarkan penelitian yang sudah dilakukan, akhirnya dapat diambil kesimpulan:

1. Penerapan algoritma kunci privat untuk enkripsi SMS pada perangkat android dapat meningkatkan keamanan. Pesan yang terenkripsi tidak akan dapat dibaca jika tidak didekripsi dengan menggunakan kunci yang benar.

2. Dengan algoritma KVC, maka hasil enkripsinya sama dengan jumlah karakter plaintextnya.

3. Waktu yang diperlukan untuk proses pengiriman SMS dengan mengunakan aplikasi SMS biasa dan dengan menggunakan aplikasi Vigenere SMS tidak berbeda. Hal ini dikarenakan pada dasarnya aplikasi Vigenere SMS ini me-link langsung ke inbox bawaan perangkat selular itu sendiri. Jadi pada aplikasi Vigenere SMS, user hanya "menumpang " untuk mengenkripsi pesan saja. 
Jurnal Riset Sistem Informasi Dan Teknik Informatika (JURASIK)

Volume (3) Juli 2018, pp 73-86

ISSN: 2527-5771/EISSN: 2549-7839

http://tunasbangsa.ac.id/ejurnal/index.php/jurasik

4. Waktu pengiriman SMS bergantung pada jaringan sinyal pengirim provider selular yang digunakan.

\section{DAFTAR PUSTAKA}

[1] Andi. Java for Mobile Programming, Wahana Komputer, Semarang 2012

[2] Ariyus, Dony, Pengantar Ilmu Kriptografi: Teori, Analisis, dan Implementasi. Penerbit Andi, Yogyakarta, 2008.

[3] Hendrayanto, Rudi dan Ramadona Nilawati. PROGRAM APLIKASI ENKRIPSI DAN DEKRIPSI SMSPADA PONSEL BERBASIS ANDROID DENGAN ALGORITMA DES. ISSN:2302-3740. Depok: Prosiding Seminar Ilmiah Nasional Komputer dan Sistem Intelijen (KOMMIT 2012)

[4] Kajian pustaka.. "Teori SMS (Short MessageService)" 2012 (http://www.kajianpustaka.com/2012/12/teori-sms-short-message-service.html). Diakses tanggal 18 Agustus 2017.

[5] Munir, Rinaldi.. Pengantar Kriptografi. Angkasa Bandung:. 2006

[6] Safaat, Nazruddin. Aplikasi Berbasis Android.: Informatika Bandung. 2013.

[7] Setiawan, Deris..Sistem Keamanan Komputer. : Elex Media Komputindo Jakarta 2005

[8] Sun-zine, Berkenalan dengan Algoritma Kriptografi Klasik: Vigènere Cipher" 2012(http://suncoolin.blogspot.co.id/2012/07/algoritma-kriptografi-klasik-Vigenere-Cipher.html) Diakses tanggal 5 Agustus 2017.

[9] Telekomunikasi. 2010. "SMS" (http://serenitysparkling.blogspot.co.id/2010/10/sms.html). Diakses tanggal 18 Agustus 2017 